\title{
Corrosion Resistance of Al-CNT Metal Matrix Composites
}

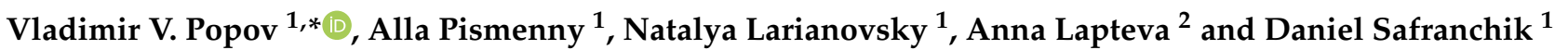 \\ 1 Institute of Metals, Technion R\&D Foundation, Haifa 3200003, Israel; allap@trdf.technion.ac.il (A.P.); \\ natalyal@trdf.technion.ac.il (N.L.); DaniS@trdf.technion.ac.il (D.S.) \\ 2 Department of Regional Economics, Innovation Enterprise and Security, Ural Federal University, \\ 620002 Ekaterinburg, Russia; annalapteva@mail.ru \\ * Correspondence: vvp@technion.ac.il
}

Citation: Popov, V.V.; Pismenny, A.; Larianovsky, N.; Lapteva, A.;

Safranchik, D. Corrosion Resistance of Al-CNT Metal Matrix Composites. Materials 2021, 14, 3530. https:// doi.org/10.3390/ma14133530

Academic Editors:

Maria Letizia Ruello

and Hendra Hermawan

Received: 22 April 2021

Accepted: 21 June 2021

Published: 24 June 2021

Publisher's Note: MDPI stays neutral with regard to jurisdictional claims in published maps and institutional affiliations.

Copyright: (c) 2021 by the authors. Licensee MDPI, Basel, Switzerland. This article is an open access article distributed under the terms and conditions of the Creative Commons Attribution (CC BY) license (https:// creativecommons.org/licenses/by/ $4.0 /)$.

\begin{abstract}
The design of aluminium-graphite metal matrix composites (MMCs) with advanced mechanical properties and high corrosion resistance is in demand for aerospace, transportation, and industrial applications. Breakthroughs in this field are limited due to the tendency of aluminiumgraphite MMCs to corrode. In the present research, aluminium-based MMCs were produced by a relatively novel combined two-staged method. Multiwall carbon nanotubes (MWCNTs) were added into molten Al1070 and processed by high-pressure die casting followed by cyclic extrusion. For the composites produced by this method, it was previously demonstrated that mechanical properties are improved in comparison with pure aluminium alloys. In the current study, the manufactured Al-MWCNT composites were investigated by electrochemical tests (such as open circuit potential), potentiodynamic tests, linear polarization tests, and electrochemical impedance spectra to understand the corrosion resistance of the obtained composite material. The experimental testing of the corrosion resistance of Al-MWCNT MMCs showed that due to the advantages of the fabrication method, the addition of CNTs to aluminium does not cause a radical decrease of corrosion resistance.
\end{abstract}

Keywords: aluminium metal matrix composites; carbon nanotubes; CNT; corrosion

\section{Introduction}

Metal matrix composites (MMCs) are of great interest to leading industries for their various applications in, for example, aerospace, transportation, defence, construction, and industry. These materials are developed for their unique combination of physical and mechanical properties, such as being lightweight, having mechanical strength, and having chemical and corrosion resistance. The control and prediction of corrosion issues are crucial for many industries [1,2], especially for aerospace applications [3-5].

Graphite-aluminium MMCs are already well-known materials for advanced industrial applications [6]. However, these MMCs are known as typically prone to corrosion. The corrosion resistance of the metal matrix composites is strongly affected by galvanic corrosion at the interfaces between the metallic matrix and its reinforcements [7]. By now, no significant progress has been achieved in the design of such MMCs with enhanced mechanical properties and sufficient corrosion resistance [7].

The problematic issue in the fabrication of aluminium-based MMCs is that alloying additions may reduce the corrosion resistance of the aluminium matrix [8]. It should be taken into account that the corrosion behaviour of graphite-aluminium composites may be strongly related to the selected production method used for their fabrication and the type of carbon-based additives [3,9].

The most typical fabrication methods for Al-based MMCs include liquid phase techniques (stir casting, strip casting, arc/laser melting, etc.), powder metallurgy (ball-milling, compaction, mixing, etc.), and deformation techniques (rolling, extrusion, etc.) [10].

The MMCs with an aluminium matrix reinforced with tungsten carbide (WC) and titanium carbide (TiC) particles are described in [11]. In this work, the authors used 
submicron-sized WC and TiC particles to reinforce Al1050 in a two-step method: mixing additives with fluxing salt followed by introducing this mix into the molten aluminium alloy. Melting was accompanied by intensive stirring to avoid agglomeration of carbides and to promote homogeneous dispersion. Molten aluminium with induced carbides was poured into moulds [11]. The authors declared that the corrosion behaviour of the obtained MMCs was determined by the corrosion resistance of the selected aluminium alloy. Moreover, carbides and aluminides in the aluminium matrix often prevented intergranular corrosion [11]. Another paper reported Al-based MMCs with SiC reinforcement designed by strip casting [12]. The MMC system that had a greater hardness had better corrosion resistance, but still lower than that of the initial aluminium alloy [12]. Shimizu et al. investigated the corrosion resistance of Al-based metal matrix composites prepared with various additives: carbon fibres, alumina fibres, and silicon carbide whiskers [9]. The authors showed that the corrosion potential for MMCs produced with carbon fibres, alumina fibres, and $\mathrm{SiC}$ whiskers was rather the same as for pure $\mathrm{Al} 6061$. However, it was concluded that the presence of carbon additives might be more subjected to pitting [9]. Zakaria showed that $\mathrm{Al} / \mathrm{SiC} \mathrm{MMCs}$ could be fabricated by powder metallurgy methods [13]. The author tested the impact of the fraction size of $\mathrm{SiC}$ additives on the corrosion behaviour of the MMCs. It was found that an increase in the amount of $\mathrm{SiC}$ in $\mathrm{MMC}$, and the reduction of its fraction size, resulted in corrosion resistance improvement [13].

The significant contribution of the publications cited above and displayed in Table 1 is devoted to the fabrication of MMCs with additives having a fraction size from several to tens of microns. The introduction and dispersion of nano-sized additives, such as carbon nanotubes (CNTs), is a challenging issue, especially by liquid phase metallurgy [14]. However, there were attempts to fabricate aluminium-based composites with CNTs by the rolling technique [15]. The obtained results showed the scalability of the fabrication method and improvement of mechanical properties, but the corrosion behaviour was not evaluated [15]. The main issue in producing Al-based composites containing CNTs by liquid phase metallurgy is to mix them homogeneously in molten aluminium. It is problematic since the CNTs tend to rise to the surface without being mixed because of their poor wetting properties and great difference in their density compared with that of $\mathrm{Al}$ [16].

Table 1. Al-based MMCs fabricated by various techniques with various reinforcement additives.

\begin{tabular}{|c|c|c|c|c|}
\hline Aluminium Alloy & Additive & Fabrication Method & Aimed Application & Ref. \\
\hline AA1050 & WC, TiC & Mixing and casting & Aerospace, defence, automotive & [11] \\
\hline AA6063 & $\mathrm{SiC}$, ash particles & Stir casting & Aerospace & [12] \\
\hline AA6063 & $\mathrm{TiC}, \mathrm{Al}_{2} \mathrm{O}_{3}$ & $\begin{array}{l}\text { In situ reaction and } \\
\text { "near-liquid casting } \\
\text { method" }\end{array}$ & Aerospace, automobile & [17] \\
\hline AA6061 & Fly ash & Stir casting & Aerospace & [18] \\
\hline Pure Al & $\begin{array}{c}\mathrm{Al}_{2} \mathrm{O}_{3}, \mathrm{SiC} \text {, graphite } \\
\text { particles }\end{array}$ & Stir casting & High-tech construction applications & [19] \\
\hline AA7178 & $\mathrm{ZrB}_{2}$ & Stir casting & Aerospace, automobile & [20] \\
\hline AA6061 & $\begin{array}{c}\mathrm{C} \text { fibres, } \mathrm{Al}_{2} \mathrm{O}_{3} \text { fibres, } \\
\mathrm{SiC} \text { whiskers }\end{array}$ & Squeeze casting & Aerospace & [9] \\
\hline Pure Al & $\mathrm{Al}_{2} \mathrm{O}_{3}$ & High-energy ball milling & Aerospace, automobile & [21] \\
\hline $\begin{array}{l}\text { Al powder of } 99.8 \% \\
\text { purity }\end{array}$ & $\mathrm{SiC}$ & Mixing and compaction & Aerospace, transportation & [13] \\
\hline AA1100-H12 & MWCNTs & $\begin{array}{l}\text { Ultrasonic assembly \& } \\
\text { rolling }\end{array}$ & Aerospace, industrial applications & [15] \\
\hline AA1070 & MWCNTs & HPDC-CE & Aerospace, industrial applications & [14] \\
\hline
\end{tabular}


A combined two-staged method was developed to overcome these issues [14]. The authors developed a method of fabrication of metal matrix composites in which multiwall carbon nanotubes (MWCNTs) were inline dispersed in the Al matrix [14]. Figure 1 shows the method, which includes two main steps. The first step is high-pressure die casting (HPDC) of aluminium, where the MWCNTs are added to the short sleeve of the HPDC furnace prior to aluminium incorporation. In the second step, the obtained cast ingot passes ten cycles of extrusion (CE) to break up agglomerated MWCNTs clusters and to align them in the direction of extrusion.

High-pressure die casting

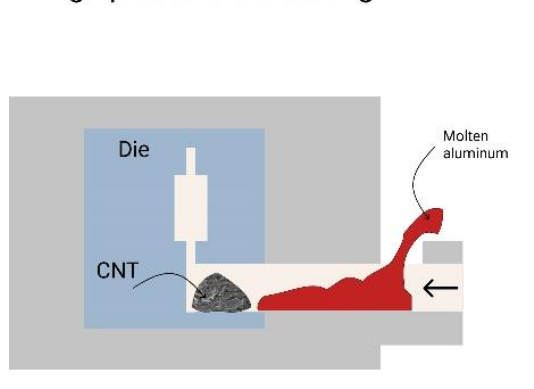

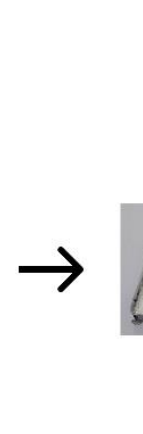

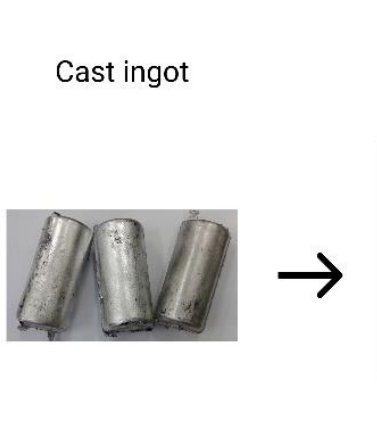

\section{Cyclic extrusion}

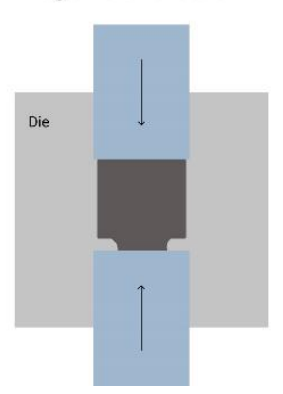

Extruded ingot

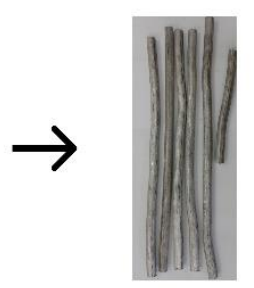

Figure 1. Workflow of HPDC-CE fabrication method.

The introduction of carbon nanotubes in aluminium and their distribution have a crucial effect on the electrical and mechanical properties of the resulting composites [22,23]. Accordingly, it is logical to expect an effect on their corrosion resistance. Therefore, it was important in the present study to determine how the developed method of manufacturing aluminium composites using high-pressure die casting and cyclic extrusion improves or degrades the initial corrosion resistance of the aluminium alloy.

The novel HPDC-CE method used in this research enables the manufacturing of MMCs with a significant increase in mechanical strength [14]. In the present research, it was crucial for us to demonstrate that the proposed fabrication method allows reinforcement of the material without significant degradation of corrosion resistance. We investigated the corrosion behaviour of aluminium-based MMCs produced by this HPDC-CE method and compared them with a pure aluminium 1070 alloy.

The current research demonstrates how the novel production HPDC-CE method affects the corrosion resistance properties of Al-MWCNT composites.

\section{Materials and Methods}

The raw materials used were aluminium alloy Al 1070 and MWCNTs (Nanocyl SA, Sambreville, Belgium) of 90\% purity (see Figure 2 and Table 2). The experimental $\mathrm{Al}-$ MWCNT MMCs were prepared at the Israeli Institute of Metals by a high-pressure die casting technique followed by cyclic extrusion as described in [14].

Three Al-based groups of samples were characterized:

- A-pure Al 1070;

- B-Al 1070 with 0.25 wt.\% MWCNTs;

- D-Al 1070 with 0.5 wt.\% MWCNTs.

All groups of samples were produced by high-pressure die casting followed by 10 cycles of extrusion according to [14]. The examined surface of the samples was perpendicular to the extrusion direction. For each group of samples, between 3 and 5 surfaces were examined.

High-resolution SEM images were obtained with a TESCAN-MIRA3 high-resolution field emission gun (FEG) scanning electron microscope (Zeiss Ultra, Oberkochen, Germany), equipped with the AZtecHKL standard package. 

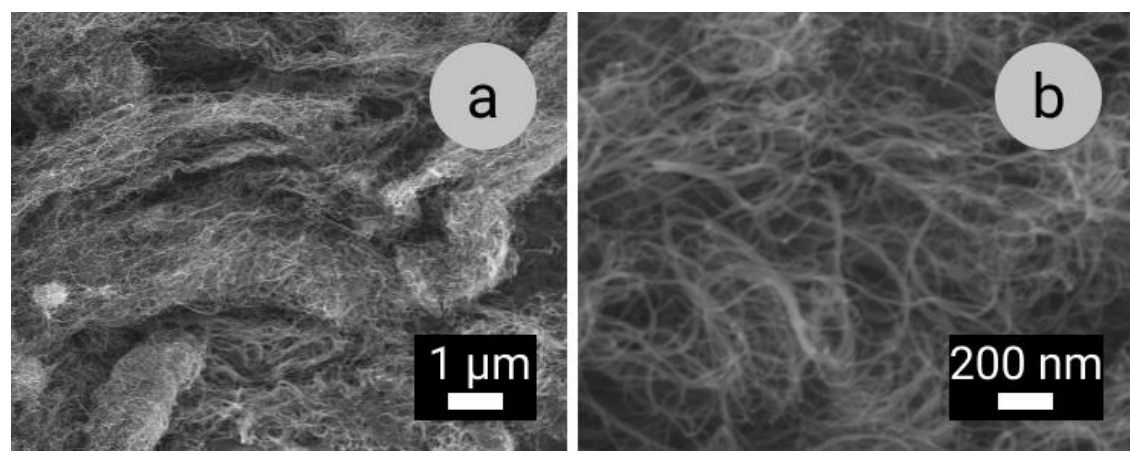

Figure 2. Scanning electron microscopy images of as-received MWCNTs at: (a) lower (10.00 K) and (b) higher $(50.00 \mathrm{~K})$ magnifications.

Table 2. Specification of MWCNTs by Nanocyl SA, Sambreville, Belgium.

\begin{tabular}{ccccc}
\hline Type & Outer Diameter, $\mathbf{n m}$ & Length, $\boldsymbol{\mu m}$ & Purity, wt. $\%$ & ${\text { Surface Area, } \mathbf{m}^{2} / \mathbf{g}}^{2}$ \\
\hline NC7000 Nanocyl SA & 9.5 & 1.5 & 90 & $250-300$ \\
\hline
\end{tabular}

The HPDC-CE samples were cut and polished for microstructural examination using standard SiC grit papers and required emulsions. The final grid paper was of 4000 mesh for $60 \mathrm{~s}$. The samples had a diameter of $10 \mathrm{~mm}$ and height $8 \mathrm{~mm}$. The samples for corrosion testing were cut and polished strictly under the same conditions.

Corrosion measurements were conducted for the pure aluminium specimen as a reference and for the HPDC-CE produced MMCs using the electrochemical cyclic polarization technique according to [24]. The scheme of the corrosion resistance potentiodynamic measurement is shown in Figure 3. Electrochemical measurements were performed at room temperature in a $3 \% \mathrm{NaCl}$ solution with $\mathrm{pH}=7.2$ before testing. The saturated Calomel electrode (sat'd $\mathrm{KCl}$ ) was used according to the standard [24]. The parameters of electrochemical measurements, including repeatable electrochemical impedance spectroscopy, are shown in Table 3.

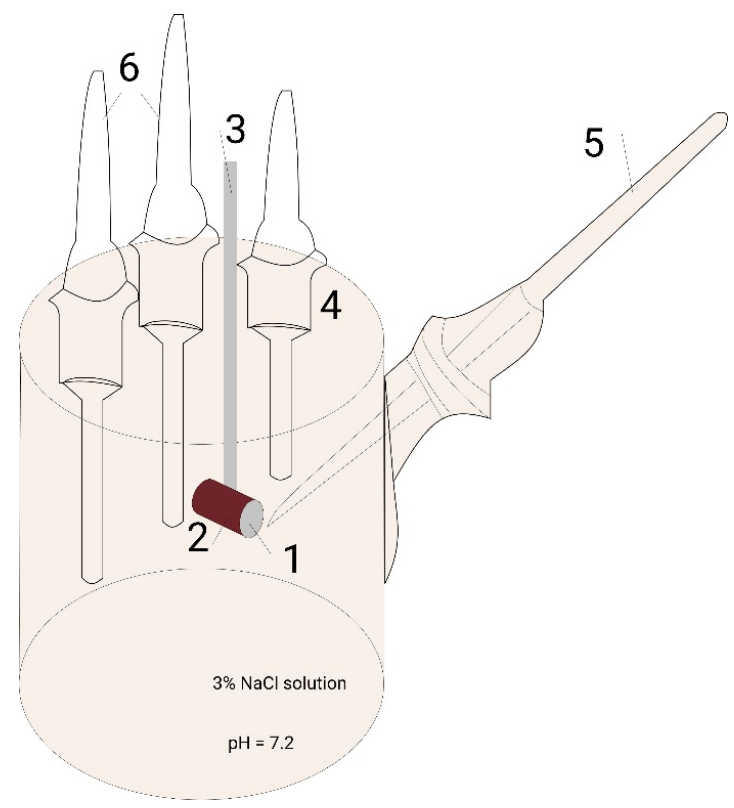

Figure 3. Experimental scheme of corrosion potential testing by potentiodynamic anodic polarization technique, where 1: tested sample surface (working electrode); 2 : isolate sample with only one tested surface; 3 : sample holder; 4 : testing glass with $3 \% \mathrm{NaCl}$ solution with $\mathrm{pH}=7.2 ; 5$ : Calomel electrode with probe membrane; and 6: auxiliary electrode holders. 
Table 3. Testing conditions and parameters.

\begin{tabular}{|c|c|c|c|c|c|c|}
\hline \multicolumn{7}{|c|}{ Potentiodynamic Test } \\
\hline Test cell & Solution & Temperature & $\begin{array}{c}\text { Er } \\
\text { equilibrium }\end{array}$ & Potentiostat & $\begin{array}{l}\text { Auxiliary } \\
\text { electrodes }\end{array}$ & Reference electrode \\
\hline $\begin{array}{l}\text { Glass bulb } \\
\text { with } 0.8 \mathrm{~L} \text { of } \\
\text { test solution }\end{array}$ & $0.1 \mathrm{~N} \mathrm{NaCl}$ & $25 \pm 1^{\circ} \mathrm{C}$ & $30 \mathrm{~min}$ & $\begin{array}{l}\text { Gamry } \\
\text { Reference } \\
3000\end{array}$ & Graphite (X1) & $\begin{array}{l}\text { Saturated Calomel Electrode } \\
\text { (sat'd KCl)—SCE }\end{array}$ \\
\hline \multicolumn{7}{|c|}{ Linear polarization parameters } \\
\hline Initial E & Final E & \multicolumn{3}{|c|}{ Sample area } & \multicolumn{2}{|c|}{ Polarization scan rate } \\
\hline$-250 \mathrm{mV}$ & $+250 \mathrm{mV}$ & $\mathrm{A}-0.63 \mathrm{~cm}^{2}$ & $\mathrm{~B}-0.63 \mathrm{~cm}^{2}$ & $\mathrm{D}-0.47 \mathrm{~cm}^{2}$ & \multicolumn{2}{|r|}{$1 \mathrm{mV} / \mathrm{s}$} \\
\hline \multicolumn{7}{|c|}{ Impedance potentiostatic parameters } \\
\hline $\begin{array}{l}\text { Initial freq. } \\
(\mathrm{kHr})\end{array}$ & $\begin{array}{l}\text { Final freq. } \\
(\mathrm{mHr})\end{array}$ & \multicolumn{3}{|c|}{ Sample area } & \multicolumn{2}{|c|}{ DC voltage $(\mathrm{V})=$ Eoc } \\
\hline 100 & 10 & $\mathrm{~A}-0.63 \mathrm{~cm}^{2}$ & $\mathrm{~B}-0.63 \mathrm{~cm}^{2}$ & $\mathrm{D}-0.47 \mathrm{~cm}^{2}$ & $\operatorname{Eoc}(A)=-680$ & $\operatorname{Eoc}(B)=-744 \quad \operatorname{Eoc}(D)=-746$ \\
\hline
\end{tabular}

\section{Results}

Figure 1 shows that the used MWCNTs were strongly agglomerated, and that was why several cycles of extrusion were required to break the agglomerates and to disperse them homogeneously in the aluminium matrix.

It has been found that the amount of MWCNTs that can be introduced into an aluminium matrix by the two-staged HPDC-CE method is limited. The introduction of limited amounts of MWCNTs using the HPDC-CE method results in improving the mechanical strength. The ultimate strength was observed to be $94 \mathrm{MPa}$ for 1070 aluminium, $126.8 \mathrm{MPa}$ for $\mathrm{Al}+0.25 \% \mathrm{MWCNTs}$, and $132.2 \mathrm{MPa}$ for $\mathrm{Al}+0.5 \% \mathrm{MWCNTs}$ after the same ten number of extrusion cycles. The yield strength was also increased from $64 \mathrm{MPa}$ for the initial 1070 alloy, to $99.2 \mathrm{MPa}$ for $\mathrm{Al}+0.25 \% \mathrm{MWCNTs}$, and to $104 \mathrm{MPa}$ for $\mathrm{Al}+0.5 \%$ MWCNTs [14] The improvement of the mechanical performance of the composites with the addition of MWCNTs is due to the superior mechanical properties of these carbon nanotubes. The increase of the MWCNTs amount to higher than $0.5 \%$ leads to a reduction in mechanical properties $[14,25,26]$. Such behaviour may be attributed to the presence of MWCNT clusters that can be easily demonstrated by SEM (Figure 4).

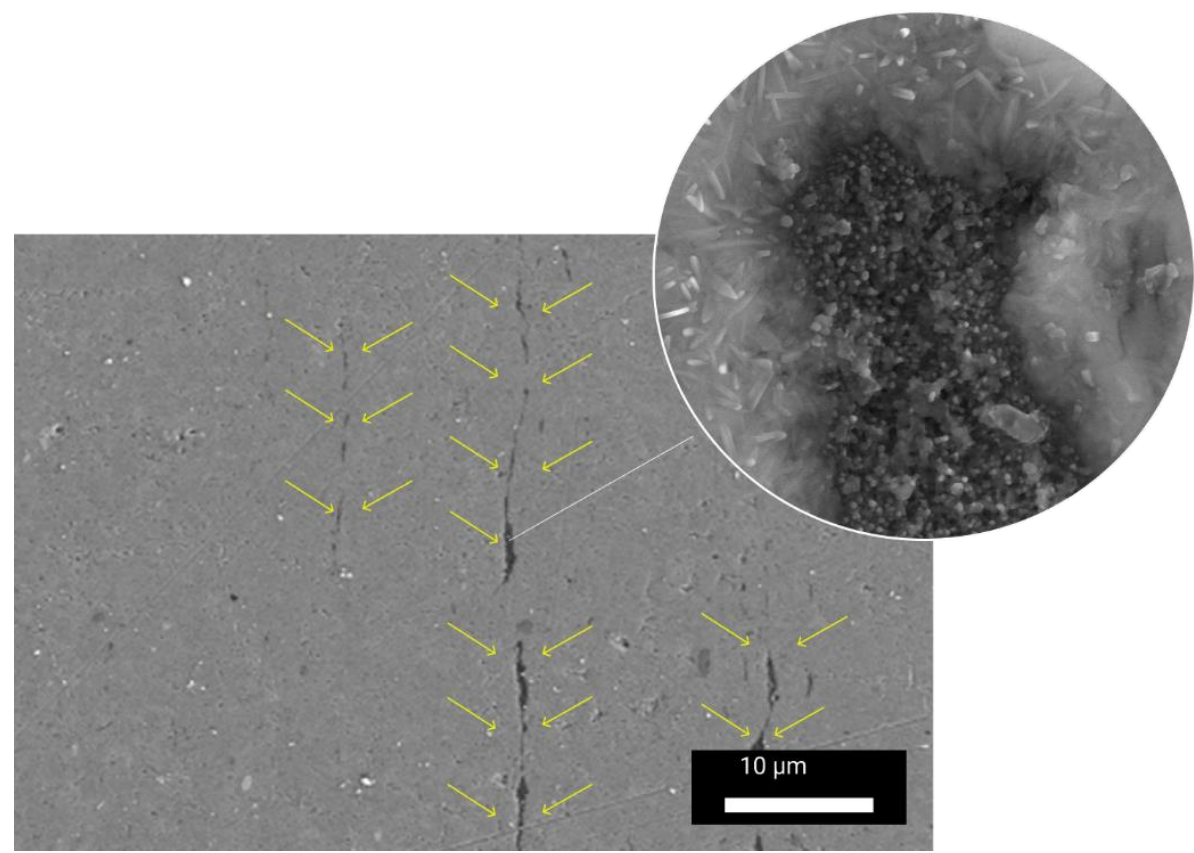

Figure 4. HRSEM images of the $\mathrm{Al}-0.5 \mathrm{wt}$.\% CNT composites after 10 cycles of cyclic extrusion. MWCNT-rich clusters are signified by arrows. 
It can also be seen in Figure 4 that the CNT clusters have a specific linear character. Due to the cyclic extrusion process, it was possible to reduce the CNT clusters up to $200 \mathrm{~nm}$. They are aligned in the direction of extrusion and look like parallel passes in cylindrical samples. This makes possible the properties of anisotropy in line with the extrusion direction and in the surfaces perpendicular to it.

Sample A-pure aluminium has been tested to demonstrate the corrosion resistance of aluminium as a reference. Figure $5 a$ shows the initial surface for the test, and Figure $5 b$ shows the surface after testing. The light pitting corrosion of the sample A surface can be observed. Figure $5 \mathrm{c}$ shows areas of cracking of the material surface in the pitting zone. Figure 5d,g shows the initial surfaces of the samples B and D, correspondingly, before tests. For both composite samples, the same pitting behaviour can be observed (see Figure 5e,h). At a higher magnification (Figure 5f,i), it can be seen that in composite samples, pitting looks more aggressive in CNT clusters areas. This can be explained by the fact that Al-based composites are more prone to pitting than pure aluminium alloys without reinforcement $[7,27]$. It is also a well-known fact that pitting is one of the main corrosion types for aluminium alloys and the composites based on them [17,28].

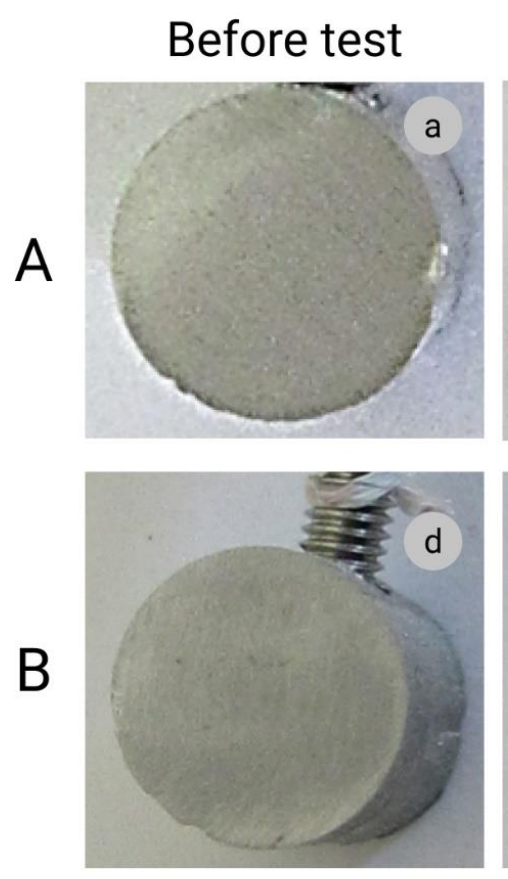

\section{After test: general view and features}
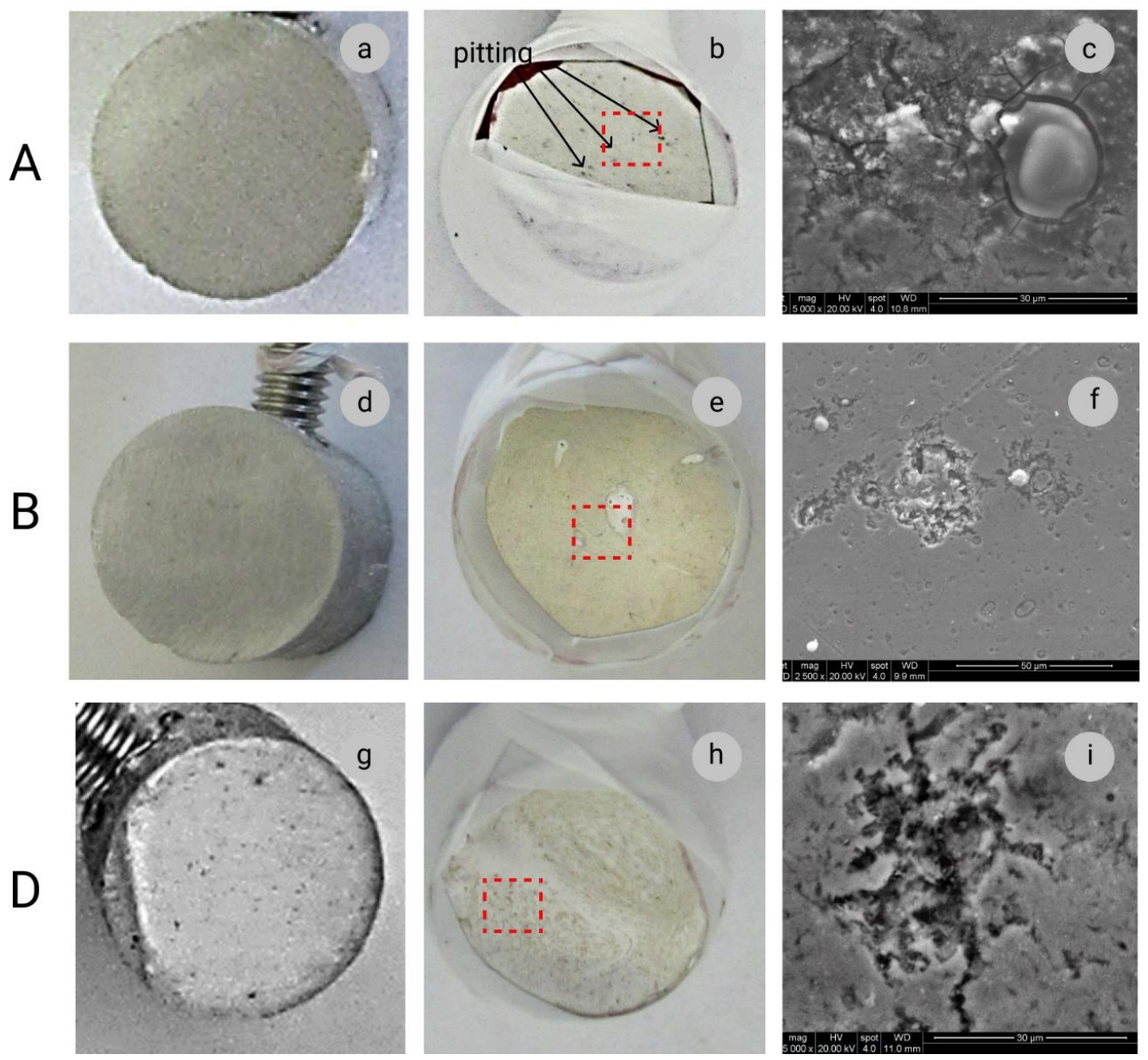

Figure 5. Sample A-pure aluminium 1070 produced by die casting and direct extrusion: (a)—the test surface before the test; (b)—image of the sample's surface after the test; (c)—SEM image of specific features on the sample's surface because of corrosion. Sample B-Al-based composite sample with $0.25 \mathrm{wt} \%$ of MWCNTs: (d)—the test surface before the test; (e)-image of the sample's surface after the test; (f) - SEM image of specific features on the sample's surface because of corrosion. Sample D—Al-based composite sample with $0.5 \mathrm{wt}$.\% of MWCNTs: (g) — the test surface before the test; (h)—image of the sample's surface after the test; (i)—SEM image of specific features on the sample's surface because of corrosion. 
The potentiodynamic polarization curves of the aluminium 1070 alloy and the AlMWCNT composites are shown in Figure 6. The corresponding Tafel results are shown in Table 4 . The potentiodynamic polarization curves of all samples were basically the same in shape, which indicates that these two materials have similar electrochemical corrosion behaviour in $3 \% \mathrm{NaCl}$ solution. The polarization curves do not show passive regions; therefore, the corrosion type of the two materials in the $3 \% \mathrm{NaCl}$ solution is an active corrosion process [17]. However, according to the fitting results of the polarization curves, the composite samples have a lower corrosion potential and almost the same corrosion current density compared with those of the 1070 aluminium alloy. Due to the pitting type of corrosion in all groups of samples, the corrosion rate could not be calculated.

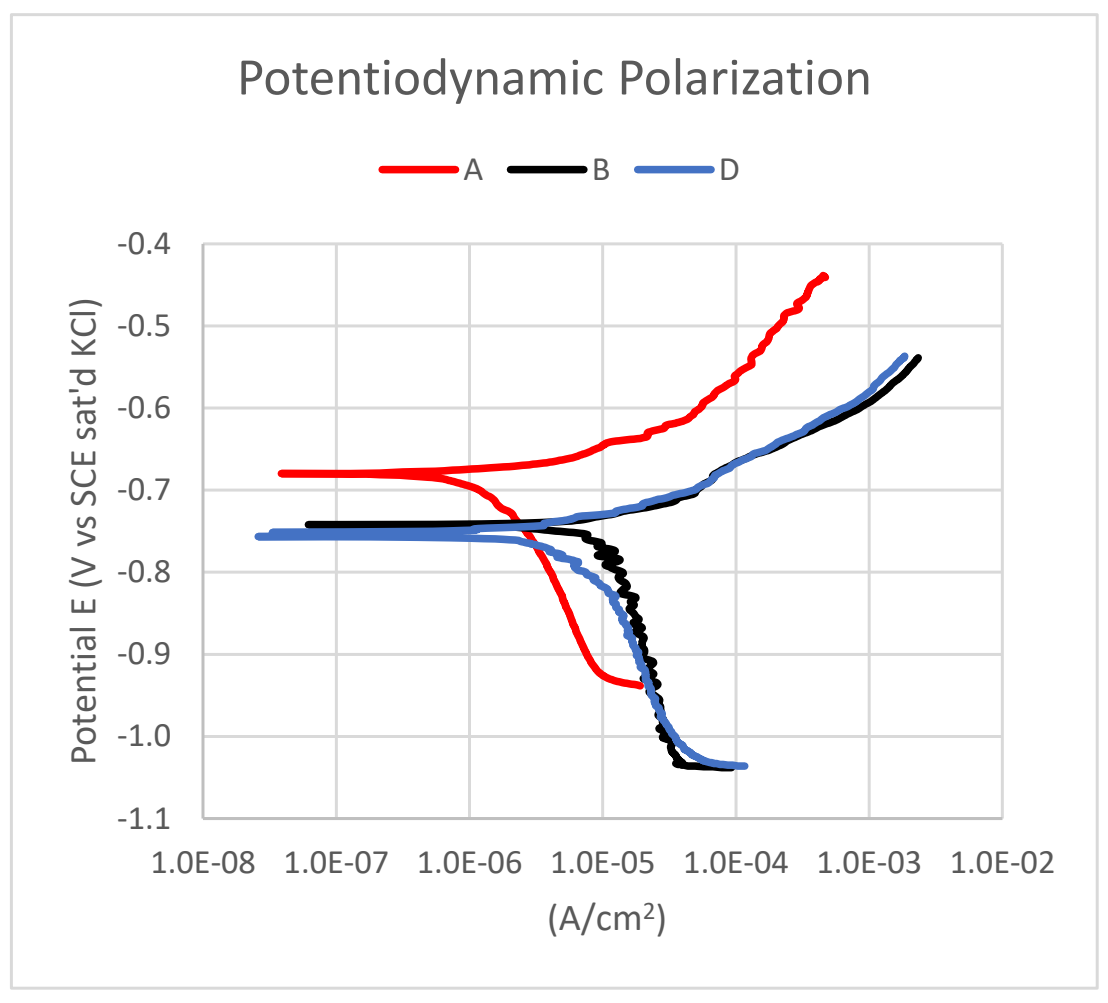

Figure 6. Potentiodynamic electrochemical measurement of sample A-pure aluminium 1070; sample B-Al $1070+0.25$ wt.\% MWCNTs; and sample D-Al $1070+0.5$ wt. \% MWCNTs.

Table 4. Potentiodynamic measurement results for selected group of samples.

\begin{tabular}{|c|c|c|c|c|c|c|c|}
\hline \multirow{2}{*}{ Sample } & \multirow{2}{*}{ Material } & \multirow{2}{*}{$\begin{array}{c}\text { Approximate Surface } \\
\text { Area }\left(\mathrm{cm}^{2}\right)\end{array}$} & \multirow{2}{*}{$\begin{array}{c}\mathrm{E}_{\text {cor }}(\mathrm{mV}) \text { after } \\
0.5 \text { h vs. SCE }\end{array}$} & \multirow{2}{*}{$\begin{array}{l}E_{\text {cor }}(m V) \text { after } \\
1 \text { h vs. SCE }\end{array}$} & \multirow{2}{*}{$\begin{array}{l}\mathrm{I}_{\mathrm{cor}} \\
(\mu \mathrm{A})\end{array}$} & \multicolumn{2}{|c|}{$\mathrm{pH}$} \\
\hline & & & & & & Before Test & After Test \\
\hline $\mathrm{A}$ & Al1070 & 0.63 & -689 & -680 & 0.03 & 7.05 & 6.54 \\
\hline B & $\begin{array}{c}\mathrm{A} 11070+ \\
0.25 \%(w / w) \\
\text { MWCNTs }\end{array}$ & 0.63 & -789 & -44 & 0.06 & 7.0 & 6.74 \\
\hline $\mathrm{D}$ & $\begin{array}{c}\text { Al1070+ } \\
0.5 \%(w / w) \\
\text { MWCNTs }\end{array}$ & 0.47 & -787 & -746 & 0.04 & 7.1 & 6.7 \\
\hline
\end{tabular}

Figure 7 shows the open circuit potential (OPC) linear polarization curves. The OPC confirms the results of the potentiodynamic data: the corrosion potential of composite samples is lower than it is for the 1070 alloy sample. It can also be concluded that sample 
D, with a concentration of MWCNTs two times higher than sample B, has the same corrosion potential.

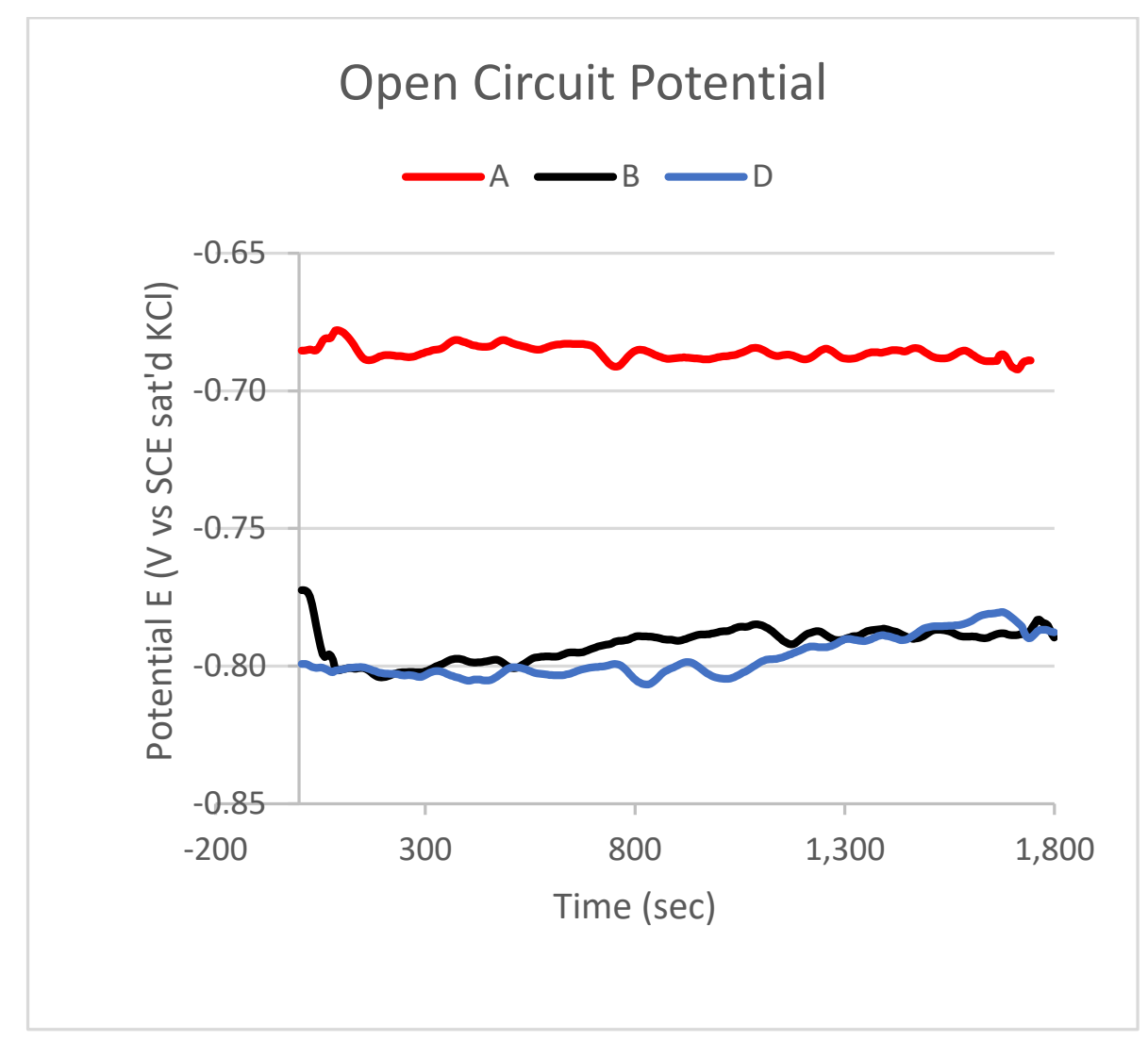

Figure 7. Open circuit potential measurement of sample A—pure aluminium 1070; sample B-Al $1070+0.25$ wt. $\%$ MWCNTs; and sample D-Al $1070+0.5$ wt. $\%$ MWCNTs.

Figure 8 shows the electrochemical impedance spectrum (EIS) aiming to provide more information about the mechanism of the corrosion reaction of the 1070 alloy (sample A) and Al-MWCNT composites (samples B and D). In the Nyquist EIS, one can observe two capacitive loops at high and intermediate frequencies and an inductive loop at low frequencies. The high-frequency loop is associated with the electron transfer process in the interface metal/oxide [29]. At low frequencies, because of the high dispersion, there is no steady state in the impedance diagram, and it is challenging to observe the inductive loop. Some authors suggest significantly increased stabilization times up to $96 \mathrm{~h}$ to reach steady state [30]. All three spectra demonstrate the inductive character in the Nyquist plot. The inductive behaviour is attributed to the active nucleation of pits [31]. The impedance spectra of the 1070 alloy and the composite samples have capacitive loops at high frequencies. However, the capacitive loop of sample A (pure 1070 alloy) shows a larger diameter than the loops of the composites (samples B and D). The high-frequency loop is related to the oxide film on the aluminium surface under the corrosion process, and the large diameter of the capacitive reactance indicates that the impedance of the oxide film is higher. The inductive loops of all samples are affected by $\mathrm{Cl}^{-}$adsorption caused by the destruction of the oxide film on the surface of the sample [17,32]. The equivalent electrical circuit fitting results are shown in Table 5. Table 5 shows that an increase of MWCNT content results in a reduction of polarization resistance $\left(R_{p}\right)$. 


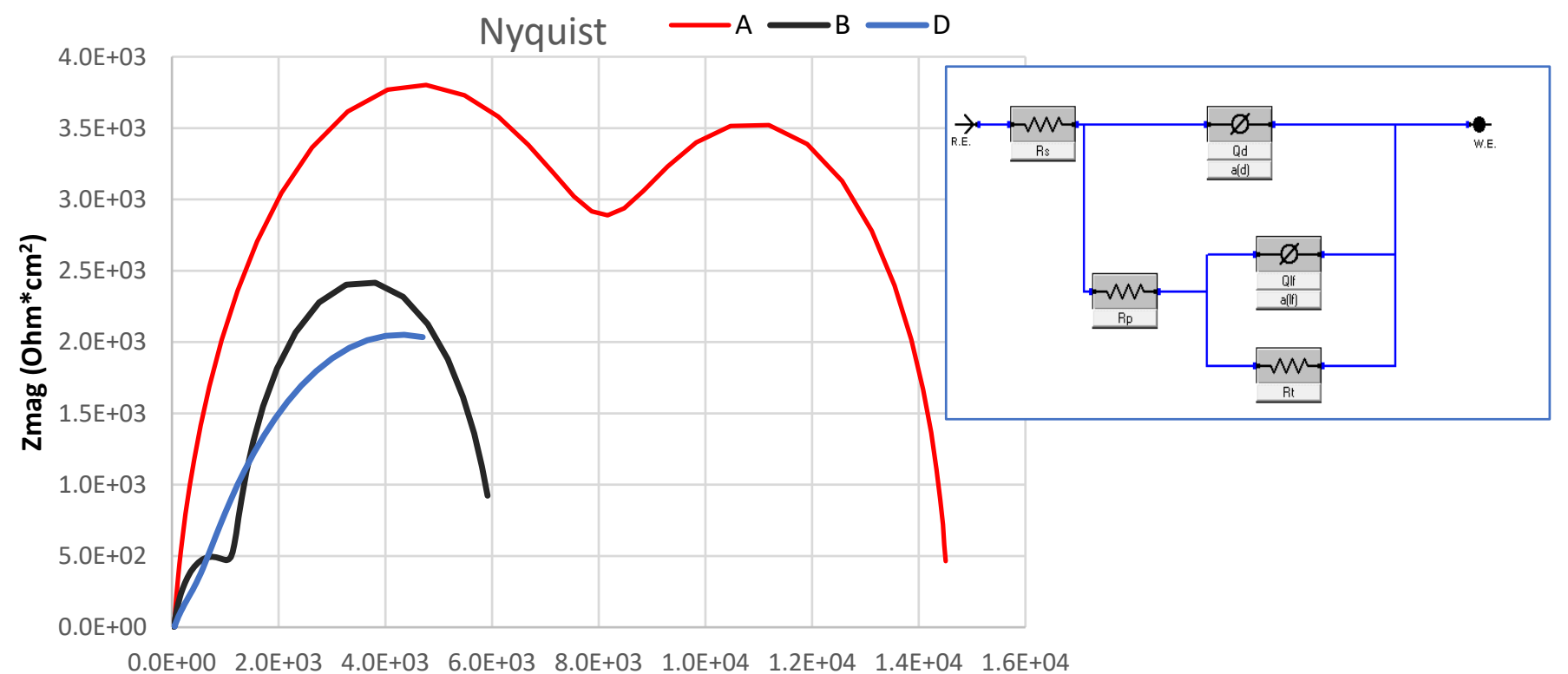

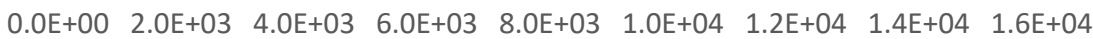

Zre $\left(\mathrm{Ohm}^{*} \mathrm{~cm}^{2}\right)$

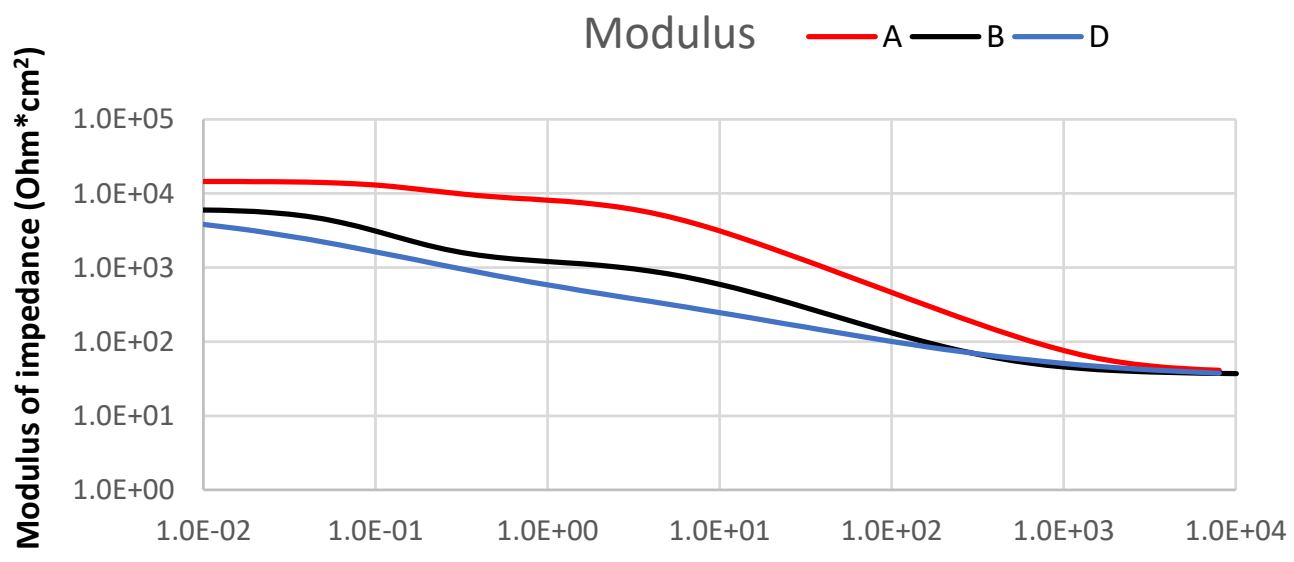

Freq. (Hz)
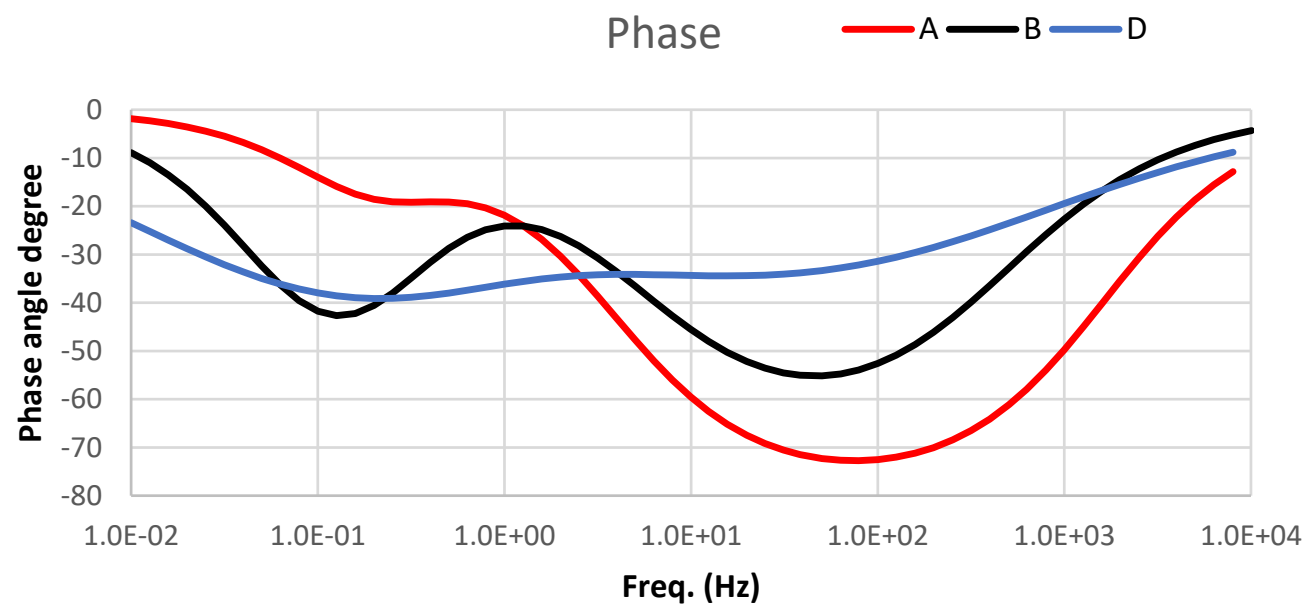

Figure 8. Electrochemical impedance spectra of sample A—pure aluminium 1070; sample B-Al $1070+0.25 \mathrm{w} . \%$ MWCNTs; and sample D-Al 1070+0. 5w.\% MWCNTs. 
Table 5. Impedance spectrum fitting results of the initial 1070 alloy and the composite samples.

\begin{tabular}{|c|c|c|c|c|c|c|c|c|}
\hline \multirow{2}{*}{ Sample } & Surface & Rs & Qd & \multirow{2}{*}{$a(d)$} & $\mathbf{R p}$ & Qlf & \multirow{2}{*}{ a(lf) } & Rt \\
\hline & $\left(\mathrm{cm}^{2}\right)$ & $\left(\mathrm{Ohm}^{*} \mathrm{~cm}^{2}\right)$ & $\left(S^{*} \sec ^{\wedge} a / c^{2}\right)$ & & $\left(\mathrm{Ohm}^{*} \mathrm{~cm}^{2}\right)$ & $\left(S^{*} \sec ^{\wedge} a / c^{2}\right)$ & & $\mathrm{Ohm}^{*} \mathrm{~cm}^{2}$ \\
\hline A & 0.63 & 39 & $7.12 \times 10^{-6}$ & 0.89 & $9.00 \times 10^{3}$ & $1.79 \times 10^{-4}$ & 1 & $5.51 \times 10^{3}$ \\
\hline $\mathrm{B}$ & 0.63 & 36 & $4.99 \times 10^{-5}$ & 0.80 & $1.34 \times 10^{3}$ & $5.45 \times 10^{-4}$ & 1 & $4.78 \times 10^{3}$ \\
\hline $\mathrm{D}$ & 0.47 & 32 & $3.60 \times 10^{-4}$ & 0.54 & $5.64 \times 10^{2}$ & $5.26 \times 10^{-4}$ & 0.5 & $2.54 \times 10^{4}$ \\
\hline
\end{tabular}

The quantitative data on corrosion potential measurements for all the three groups of samples are summarized in Table 4.

The results collected in Table 4 and the graphs in Figures 6-8 demonstrate that the MWCNT content does not radically affect the corrosion resistance of the produced Al-based MMCs. However, the corrosion potential value for pure aluminium is $-680 \mathrm{mV}$, and for the obtained composite samples, it is $-745 \mathrm{mV}$ relative to the SCE saturated calomel (saturated $\mathrm{KCl}$ ), that is, the potential for composites is lower by $65 \mathrm{mV}$ with the MWCNT content. The developed Al-based MWCNT MMCs have the same corrosion mechanism and comparable corrosion resistance as the initial aluminium alloy.

\section{Conclusions}

In the present study, the corrosion behaviour of Al-based metal matrix composites (MMCs) containing multiwall carbon nanotubes (MWCNTs) has been investigated. The Al-MWCNT composites were fabricated by the two-stage melt-based HPDC-CE method.

The development of new hybrid/mixing/combined techniques is still underway and requires the improvement of CNT dispersion in the aluminium matrix. This might result in high mechanical performance and sufficient corrosion resistance.

In the researched specimens, the MWCNT clusters were observed in the extrusion direction. However, cyclic extrusion facilitates the MWCNT alignment in this direction, which is accompanied with the strengthening of the MMCs. In spite of the clusters/agglomerates issue, the combination of high-pressure die casting and cyclic extrusion for manufacturing Al-MWCNT metal matrix composites promises many benefits, namely the effectiveness of the introduction of MWCNTs, inline alignment of the MWCNTs, low waste of material, mechanical strength improvement, and reasonable corrosion resistance properties.

The inclusion and distribution of carbon nanotubes in aluminium using the proposed fabrication technique changes the corrosion potential of the composites in comparison with 1070 alloy. The tests show the same pitting mechanism of corrosion for all examined samples. The produced Al-MWCNT composites that have a higher mechanical strength are characterized by a more negative corrosion potential. Still, this can be considered as a positive result for the further development of the fabrication method of Al-based MWCNT composites. The presented experimental findings illustrate a pathway to new applications where lightweight materials with mechanical strength and reasonable corrosion resistance are of great demand, such in the aerospace industry, the gas and oil industry, and defenceoriented products.

Author Contributions: Investigation and experiments, V.V.P. and N.L.; Measurements and sample characterization, V.V.P., N.L., A.L. and A.P.; Writing—original draft preparation, V.V.P., A.P., A.L. and D.S.; Writing-review and editing, V.V.P., A.L. and D.S. All authors have read and agreed to the published version of the manuscript.

Funding: This research received no external funding.

Institutional Review Board Statement: Not applicable.

Informed Consent Statement: Not applicable.

Data Availability Statement: The data presented in this study are available on request from the corresponding author. The data are not publicly available due to confidentiality. 
Acknowledgments: This article is based upon work from COST Action CA15102 "CRM-EXTREMESolutions for Critical Raw Materials under Extreme Conditions" and COST Innovators' Grant IG15102 "ITHACA-Innovative and sustainable TecHnologies for reducing critical raw mAterials dependence for Cleaner transportation Applications" supported by COST (European Cooperation in Science and Technology) www.cost.eu.

Conflicts of Interest: The authors declare no conflict of interest.

\section{References}

1. Tsai, Y.-H.; Wang, J.; Chien, W.-T.; Wei, C.-Y.; Wang, X.; Hsieh, S.-H. A BIM-based approach for predicting corrosion under insulation. Autom. Constr. 2019, 107, 102923. [CrossRef]

2. Sun, L.; Li, C.; Zhang, C.; Su, Z.; Chen, C. Early Monitoring of Rebar Corrosion Evolution Based on FBG Sensor. Int. J. Struct. Stab. Dyn. 2017, 18, 1840001. [CrossRef]

3. Latanision, R.M. Corrosion Resistance of Metal Matrix Composites; Massachusetts Inst of Tech Cambridge Dept of Materials Science and Engineering: Cambridge, MA, USA, 1992.

4. Koli, D.K.; Agnihotri, G.; Purohit, R. Advanced Aluminium Matrix Composites: The Critical Need of Automotive and Aerospace Engineering Fields. Mater. Today Proc. 2015, 2, 3032-3041. [CrossRef]

5. Katz-Demyanetz, A.; Popov, V.V.; Kovalevsky, A.; Safranchik, D.; Koptyug, A. Powder-bed additive manufacturing for aerospace application: Techniques, metallic and metal/ceramic composite materials and trends. Manuf. Rev. 2019, 6, 5. [CrossRef]

6. Srinivasan, V.; Kunjiappan, S.; Palanisamy, P. A brief review of carbon nanotube reinforced metal matrix composites for aerospace and defense applications. Int. Nano Lett. 2021. [CrossRef]

7. Hihara, L.H.; Latanision, R.M. Corrosion of metal matrix composites. Int. Mater. Rev. 1994, 39, 245-264. [CrossRef]

8. Sharma, R.; Singh, A.K.; Arora, A.; Pati, S.; De, P.S. Effect of friction stir processing on corrosion of Al-TiB2 based composite in 3.5 wt.\% sodium chloride solution. Trans. Nonferrous Met. Soc. China 2019, 29, 1383-1392. [CrossRef]

9. Shimizu, Y.; Nishimura, T.; Matsushima, I. Corrosion resistance of Al-based metal matrix composites. Mater. Sci. Eng. A 1995, 198, 113-118. [CrossRef]

10. Qi, Y.; Kosinova, A.; Lakin, E.; Popov, V.; Rabkin, E.; Lapovok, R. Effect of SPD Processing on the Strength and Conductivity of AA6061 Alloy. Adv. Eng. Mater. 2019, 21, 1801370. [CrossRef]

11. Lekatou, A.; Karantzalis, A.E.; Evangelou, A.; Gousia, V.; Kaptay, G.; Gácsi, Z.; Baumli, P.; Simon, A. Aluminium reinforced by WC and TiC nanoparticles (ex-situ) and aluminide particles (in-situ): Microstructure, wear and corrosion behavior. Mater. Des. 2015, 65, 1121-1135. [CrossRef]

12. Aribo, S.; Fakorede, A.; Ige, O.; Olubambi, P. Erosion-corrosion behaviour of aluminum alloy 6063 hybrid composite. Wear 2017, 376-377, 608-614. [CrossRef]

13. Zakaria, H.M. Microstructural and corrosion behavior of Al/SiC metal matrix composites. Ain Shams Eng. J. 2014, 5, 831-838. [CrossRef]

14. Larianovsky, N.; Popov, V.; Katz-Demyanetz, A.; Fleisher, A.; Meyers, D.E.; Chaudhuri, R.S. Production of Al Metal Matrix Composites Reinforced with Carbon Nanotubes by Two-Stage Melt-Based HPDC-CE Method. J. Eng. Mater. Technol. Trans. ASME 2019, 141, 011002. [CrossRef]

15. Shahsavar, S.; Ketabchi, M.; Bagherzadeh, S. Fabrication of robust aluminum-carbon nanotube composites using ultrasonic assembly and rolling process. Int. J. Miner. Metall. Mater. 2021, 28, 160-167. [CrossRef]

16. Noguchi, T.; Magario, A.; Fukazawa, S.; Shimizu, S.; Beppu, J.; Seki, M. Carbon Nanotube/Aluminium Composites with Uniform Dispersion. Mater. Trans. 2004, 45, 602-604. [CrossRef]

17. Ao, M.; Liu, H.; Dong, C.; Feng, S.; Liu, J. Degradation mechanism of 6063 aluminium matrix composite reinforced with TiC and Al2O3 particles. J. Alloys Compd. 2021, 859, 157838. [CrossRef]

18. Bhandakkar, A.; Prasad, R.C.; Sastry, S.M.L. Deformation Behaviour of Aluminium Alloy AA6061-10\% Fly Ash Composites for Aerospace Application. In Advanced Composites for Aerospace, Marine, and Land Applications; Sano, T., Srivatsan, T.S., Peretti, M.W., Eds.; Springer International Publishing: Cham, Switzerland, 2016; pp. 3-21. [CrossRef]

19. Paul, R.C.; Joseph, R.; Kumar, V.N.; Devi, P.B.; Manigandan, S. Experimental analysis of hybrid metal matrix composite reinforced with $\mathrm{Al}_{2} \mathrm{O}_{3}$ and graphite. Int. J. Ambient Energy 2019, 1-5. [CrossRef]

20. Kumar, S.D.; Ravichandran, M.; Jeevika, A.; Stalin, B.; Kailasanathan, C.; Karthick, A. Effect of ZrB 2 on microstructural, mechanical and corrosion behaviour of aluminium (AA7178) alloy matrix composite prepared by the stir casting route. Ceram. Int. 2021, 47, 12951-12962. [CrossRef]

21. Mahboob, H.; Sajjadi, S.A.; Zebarjad, S.M. Influence of nanosized $\mathrm{Al}_{2} \mathrm{O}_{3}$ weight percentage on microstructure and mechanical properties of Al-matrix nanocomposite. Powder Metall. 2011, 54, 148-152. [CrossRef]

22. Xu, C.L.; Wei, B.Q.; Ma, R.Z.; Liang, J.; Ma, X.K.; Wu, D.H. Fabrication of aluminum-carbon nanotube composites and their electrical properties. Carbon N. Y. 1999, 37, 855-858. [CrossRef]

23. Liu, Z.Y.; Xiao, B.L.; Wang, W.G.; Ma, Z.Y. Singly dispersed carbon nanotube/aluminum composites fabricated by powder metallurgy combined with friction stir processing. Carbon N. Y. 2012, 50, 1843-1852. [CrossRef]

24. ASTM International. G5 Standard Reference Test Method for Making Potentiodynamic Anodic Polarization Measurements; ASTM International: West Conshohocken, PA, USA, 2014. 
25. Esawi, A.M.K.; el Borady, M.A. Carbon nanotube-reinforced aluminium strips. Compos. Sci. Technol. 2008, 68, 486-492. [CrossRef]

26. Kwon, H.; Takamichi, M.; Kawasaki, A.; Leparoux, M. Investigation of the interfacial phases formed between carbon nanotubes and aluminum in a bulk material. Mater. Chem. Phys. 2013, 138, 787-793. [CrossRef]

27. Pardo, A.; Merino, M.C.; Merino, S.; Viejo, F.; Carboneras, M.; Arrabal, R. Influence of reinforcement proportion and matrix composition on pitting corrosion behaviour of cast aluminium matrix composites (A3xx.x/SiCp). Corros. Sci. 2005, 47, 1750-1764. [CrossRef]

28. Xia, P.; Liu, Z.; Bai, S.; Lu, L.; Gao, L. Enhanced fatigue crack propagation resistance in a superhigh strength Al-Zn-Mg-Cu alloy by modifying RRA treatment. Mater. Charact. 2016, 118, 438-445. [CrossRef]

29. Peng, G.S.; Chen, K.H.; Fang, H.C.; Chao, H.; Chen, S.Y. EIS study on pitting corrosion of 7150 aluminum alloy in sodium chloride and hydrochloric acid solution. Mater. Corros. 2010, 61, 783-789. [CrossRef]

30. Rendón, M.V.; Calderón, J.A.; Fernández, P. Evaluation of the corrosion behavior of the al-356 alloy in NaCI solutions. Quim. Nova 2011, 34, 1163-1166. [CrossRef]

31. Arrabal, R.; Mingo, B.; Pardo, A.; Mohedano, M.; Matykina, E.; Rodríguez, I. Pitting corrosion of rheocast A356 aluminium alloy in 3.5wt.\% NaCl solution. Corros. Sci. 2013, 73, 342-355. [CrossRef]

32. Salazar, J.M.G.D.; Ureña, A.; Manzanedo, S.; Barrena, M.I. Corrosion behaviour of AA6061 and $\mathrm{AA}_{7005}$ reinforced with $\mathrm{Al}_{2} \mathrm{O}_{3}$ particles in aerated 3.5\% chloride solutions: Potentiodynamic measurements and microstructure evaluation. Corros. Sci. 1998, 41 , 529-545. [CrossRef] 